\title{
Closed-Loop Iterative Learning Control for Fractional-Order Linear Singular Time-Delay System: $P D^{\alpha}-$ Type
}

\author{
Mihailo Lazarević ${ }^{1)}$ \\ Boško Cvetković ${ }^{1)}$ \\ Petar Mandić1 ${ }^{1)}$
}

\begin{abstract}
In this paper a closed-loop $P D^{\alpha}$ - type iterative learning control (ILC) of fractional order linear singular time-delay system is considered. The sufficient conditions for the convergence in time domain of the proposed $P D$-alpha type ILC for a class of fractional order singular system are given by the corresponding theorem together with its proof. Also, for the first time, we proposed a proposed ILC $P D^{\alpha}$ type for a given class of uncertain, fractional order, singular systems. Finally, the validity of the proposed $P D^{\alpha}$ ILC scheme for a class of fractional order singular time-delay system is verified by a numerical example.
\end{abstract}

Key words: singular system, linear system, delay system, robotized system, closed loop, convergence, control algorithm, iterative control.

\section{Introduction}

I TERATIVE learning control (ILC) is one of the recent topics in control theories which belongs to the intelligent control methodology[1-4]. Conventional control algorithms do not take advantage of the repetitiveness and ILC is a powerful control concept that iteratively improves the behavior of processes that are repetitive in nature. Iterative learning control was described by Uchiyama in 1978 [5] in Japanese, but only few people noticed it. Arimoto et al. [6] developed the ILC idea and studied the effective control algorithm for robotic system, and now it has become a hot issue in the field of control theory and has attracted broad attention over the past decades. ILC is an approach for improving the transient performance of systems that operate repetitively over a fixed time interval. Emulating human learning, ILC uses knowledge obtained from the previous trial to adjust the control input for the current trial so that a better performance can be achieved. Namely, ILC is a trajectory tracking improvement technique for control systems, which can perform the same task repetitively in a finite time interval to improve the transient response of a system using the previous motion. The key theme of ILC is to compose an upgraded control command for the next operation with its own proportional, integral, and/or derivative tracking errors at the previous operation. The objective is that the sequential ILC inputs stimulate the system to track a desired trajectory as perfect as possible as the operation approaches infinity [7]. It has been widely acknowledged that ILCs perform well for general dynamical systems $[8,9]$.

Also, ILC requires less a priori knowledge about the controlled system in the controller design phase and also less computational effort than many other kinds of control. The study of ILC is of great significance for dynamic systems with complex modeling, uncertainty and strong nonlinear coupling, see $[10,11]$.

Since theories and learning algorithms on ILC were firstly proposed, ILC has attracted considerable interests [4] due to its simplicity and effectiveness of learning algorithm, and its ability to deal with problems with nonlinear, time-delay, uncertainties and recently singular systems. Namely, delay is very often encountered in different technical systems. It is of great significance to study time-delay systems in theory and practice, because the existence of pure time delay, regardless if it present in the control or/and state, may cause undesirable system transient response, or generally, even an instability. This motivates researches on iterative learning control to focus on systems with time delay [12].

During the past years, singular systems also known as differential-algebraic systems, semistate systems, descriptor systems, or generalized state-space systems have attracted considerable attention because of their significant applications in diverse areas [13-16]. Practically, many physical systems can be better described by singular systems than by regular systems. The conception about singular systems was originally put forward in 1974 [17]. Singular systems have more essential differences than the normal systems, due to the fact that singular systems can preserve the structure of physical systems and impulsive elements, and are widely applied in many practical control systems such as electrical network [17], power systems, robotic systems[18] economic systems, chemical processes, and network analysis [19]. Naturally, many theoretical results for regular systems have been extended to singular cases. In that way, issues of concern for singular systems are much more complicated than those for regular systems, because we need to consider not only stability, but also regularity and the absence of impulses at the same time for singular systems.

From the control point of view it is also necessary to study

\footnotetext{
1) University of Belgrade, Faculty of Mechanical Engineering, Department of Mechanics, Kraljice Marije 16, 11020 Belgrade 35, SERBIA

Correspondence to: Mihailo Lazarević; e-mail: mlazarevic@mas.bg.ac.rs
} 
the ILC for singular systems. When dealing with the ILC issue of singular systems, it becomes far more interesting and challenging, and the ILC problem of such systems has been widely discussed so far. In [20] the convergence results for a continuous linear time-invariant singular system is proposed by the close-loop PD-type iterative learning control algorithm. Further, in [21], a new iterative learning control algorithm to study the state tracking for a class of singular systems is proposed and the convergence of the algorithm is completely analyzed. In [22], they proposed PD-type ILC algorithm to study the state tracking problem for a class of discrete singular systems, then the convergence analysis of the presented algorithm is given in detail.

Recently, fractional calculus and fractional difference equations have attracted lots of authors in the past years [23-28], because they have been proved to be valuable tools in the modeling of many phenomena in engineering, physics, science, control, and they also provide an excellent tool to describe the hereditary properties of various materials and processes. Moreover, an increasing attention has been paid to fractional calculus (FC) and its application in control and modeling of fractional order singular system [29-32]. However, there are few works on the problems for singular fractional order systems with time delay as reported in the current literatures [33-35]. Besides, the fractional order iterative learning control is the latest trend in ILC research, it not only retains the advantages of the classical ILC, but also offers potential for better performances in a variety of complex physical processes. Even since the above literature suggested this good learning performance, there have been made some efforts to synthesize a better FOILC updating law for various types of fractional order systems, and we have witnessed some progress in the previous years, [36-47]. For example, a fractional-order D-type ILC algorithm was proposed in the frequency domain [36], and the convergence was investigated by means of the recursively direct discretization technique. The pioneer exploitation in the time domain was the fractional-order PD-type ILC algorithm for a class of fractional-order linear system, where the sufficient convergence of the algorithm was analyzed [37].

The most of the existing fractional-order ILC methods for fractional-order systems only focus on the non-singular systems. Moreover, an increasing attention has been paid to fractional calculus (FC) and its application in control and modeling of fractional order singular system [48-51]. Motivated by the mentioned investigations of ILC algorithms for classical singular systems, as well as ILC fractional order control in the tracking problems of these systems and taking into account that fractional-order models of these systems can be presented as singular systems of fractional order, for the first time, ILC for fractional order singular systems is suggested in paper [48]. Namely, we presented and considered in [49], robust iterative learning feedback control second-order for fractional order singular systems, and recently in [50] (P)- $P D^{\alpha}$ type ILC control as well as openclosed-loop fractional-order iterative learning control for singular fractional order system [51]. Also, some preliminary results are presented in [52] for the for singular fractional order time-delay system.

As a result, in this paper, closed-loop iterative learning control $P D^{\alpha}$ type for given fractional-order linear singular time-delay system described in the form of state space and output equations is suggested and considered. Sufficient conditions are derived in time domains which are our main contributions. Finally, we demonstrate the effectiveness of our proposed controller with simulation studies.
The remainder of this paper is arranged as follows: in Section Preliminaries, some preliminaries for $\lambda$-norm as well as the fractional Caputo operators are presented. In Section Convergence analysis of $P D^{\alpha}$ type iterative learning control, the first main result is derived where the convergence is guaranteed by mathematical proof rigorously, which includes the extensions of some of the basic result ILC of singular fractional-order systems with order $\alpha \in(0,1)$ to fractionalorder singular system with time-delay. Further, it is presented the second main result in same manner where it is considered now, singular uncertain fractional order time-delay system. In section Simulation results a suitable numerical examples are included to illustrate the performance of the proposed $P D^{\alpha}$ ILC scheme. Finally, the last section summarizes this work.

\section{Preliminaries}

\section{The $\lambda$ - norm, maximum norm, induced norm}

For later using in proving the convergence of proposed learning control, the following norms are introduced [3] for $n$ - dimensional Euclidean space $R^{n}$ : the supnorm, $\|x\|_{\infty}=\sup _{1 \leq i \leq n}\left|x_{i}\right| x=\left[x_{1}, x_{2}, \ldots x_{n}\right]^{T}$ and maximum norm $\|x\|_{s}=\max _{0 \leq t \leq T}|x(t)| \quad x=\left[x_{1}, x_{2}, \ldots x_{n}\right]^{T}$ the matrix norm as $\|A\|_{\infty}=\max _{1 \leq i \leq m}\left(\sum_{j=1}^{n}\left|g_{i, j}\right|\right) \quad A=\left[a_{i, j}\right]_{m x n}$ and the $\lambda$ - norm for a real function:

$$
\begin{gathered}
h(t), \quad(t \in[0, T]), h:[0, T] \rightarrow \mathfrak{R}^{n} \\
\|h(t)\|_{\lambda}=\sup _{t \in[0, T]} e^{-\lambda t}\|h(t)\|, \quad \lambda>0
\end{gathered}
$$

Property 1: $\lambda$ norm has the next property

$$
\begin{aligned}
& \sup _{t \in[0, T]} e^{-\lambda t} \int_{0}^{t}\|f(.)\| e^{a(t-\tau)} d \tau= \\
& \sup _{t \in[0, T]} \int_{0}^{t} e^{-\lambda t}\|f(.)\| e^{a(t-\tau)(a-\lambda)} d \tau \leq \frac{1-e^{(a-\lambda) T}}{\lambda-a}\|f(.)\|_{\lambda}
\end{aligned}
$$

Induced norm of a matrix $\mathrm{A}$ is defined as:

$$
\|A\|=\sup \left\{\frac{\|A x\|}{x}: x \in X \text { with }\|x\| \neq 0\right\}
$$

where $\|()$.$\| denotes an arbitrary vector norm. In case \|(.)\|_{\infty}$ it follows that

$$
\|A x\|_{\infty} \leq\|A\|_{\infty}\|x\|_{\infty}
$$

where $\|A\|_{\infty}$ denotes the maximum value of the matrix A. For the previous norms, note that

$$
\|h(t)\|_{\lambda} \leq\|h(t)\|_{\infty} \leq e^{\lambda T}\|h(t)\|_{\lambda} .
$$

The $\lambda$ - norm is thus equivalent to the $\infty$ - norm. For simplicity, in applying the norm $\|(.)\|_{\infty}$ the index $\infty$ will be 
omitted. Before giving the main results, we first give the following Lemma 1, [3].

Lemma 1. Suppose a real positive series $\left\{a_{n}\right\}_{1}^{\infty}$ satisfies

$$
a_{n} \leq \rho a_{n-1}+\varepsilon
$$

where $\rho \geq 0, \varepsilon \geq 0$ and $\rho<1$. Then the following holds:

$$
\lim _{n \rightarrow \infty} a_{n} \leq \varepsilon /(1-\rho) .
$$

One can notice that in case of $\varepsilon=0, \lim _{n \rightarrow \infty} a_{n} \rightarrow 0$.

\section{Fractional calculus- Caputo operator}

Fractional calculus (FC) is a mathematical topic with more than 300 years old history, but its application to physics and engineering has been reported only in the recent years. The fractional integro-differential operators are a generalization of integration and derivation to non-integer order (fractional) operators [23-28]. The three most frequently used definitions for the general fractional differ-integral are: the GrunwaldLetnikov (GL) definition, the Riemann-Liouville (RL) and the Caputo definitions, [23-28]. The definition of fractional integral is described by:

$$
{ }_{t_{0}} D_{t}^{-\alpha} f(t)=\frac{1}{\Gamma(\alpha)} \int_{t_{0}}^{t}(t-\tau)^{\alpha-1} f(\tau) d \tau, \alpha>0
$$

where $\Gamma($.$) is the well-known Euler's gamma function, which$ is defined by $\Gamma(z)=\int_{0}^{\infty} e^{-z} t^{z-1} d t$. In this paper, Caputo fractional-order operator is used, where definition of the left Caputo fractional-order derivatives is given [14, 15] as follows:

$$
\begin{aligned}
{ }_{t_{0}}^{C} D_{t}^{\alpha} f(t) & ={ }_{t_{0}} D_{t}^{\alpha-n} D^{n} f(t)= \\
& =\frac{1}{\Gamma(n-\alpha)} \int_{t_{0}}^{t}(t-\tau)^{n-\alpha-1} f^{(n)}(\tau) d \tau,
\end{aligned}
$$

where $f^{(n)}(\tau)=d^{n}(\tau) / d \tau^{n}$, is the classical $n$-order derivative, $n-1 \leq \alpha<n \in \mathbb{Z}^{+}$. In the case $n=1$ we have $0 \leq \alpha<1$ as well as

$$
{ }_{t_{0}}^{C} D_{t}^{\alpha} f(t)=\frac{1}{\Gamma(1-\alpha)} \int_{t_{0}}^{t}(t-\tau)^{-\alpha} \frac{d f(\tau)}{d \tau} d \tau .
$$

In the following sections, $D^{\alpha}$ will denote ${ }_{t 0}^{C} D_{t}^{\alpha}$ for brevity of notation.

\section{Description of Fractional order linear singular time-delay system}

In this paper, a non-integer (fractional) order singular time delay system is considered. Some examples of fractional order singular time delay systems are presented in [33-35]. To explain the essence of our proposed learning control, consider a following non-autonomous fractional order linear singular time-delay system (FOLSTDS) described by the pseudo-state space equations

$$
E D^{\alpha} \boldsymbol{x}(t)=A_{0} x(t)+A_{l} x(t-\tau)+B u(t), \quad 0<\alpha<1
$$

$$
\boldsymbol{y}(t)=C \boldsymbol{x}(t),
$$

with associated consistent function of initial state

$$
x(t)=\psi_{x}(t), \quad-\tau \leq t \leq 0 .
$$

Here, for singular systems mentioned above, matrix $\mathrm{E}$ is considered to be singular, i.e., $\operatorname{rank}[E]=r<n$, otherwise, the system (11) reduces to a standard (normal) system. In practical system analysis and control system design, some system models may be established in the form of $(11,12)$ while they could not be described by standard forms. Here, we are interested in dynamical behavior of system (11) over time interval $J=[0, T], J \subset R$, where $i$ denotes the iteration index or the operation number, $x_{i} \in R^{n}, u_{i} \in R^{m} \quad y_{i} \in R^{r}$ are the state, control input and output of the system, respectively; $A_{0} \in R^{n \times n}, A_{1} \in R^{n \times n} . B \in R^{n \times m}, C \in R^{r \times n}$ are constant matrices as well as $E$ is a singular square matrix. Also, $D^{\alpha}$ denotes the $\alpha$ th-order Caputo fractional derivative, $0<\alpha<1$, and $\tau \leq T$ denotes pure time-delay.

Definition 1. a)The SFOS system (11) is said to be regular if $\operatorname{det}\left(s^{\alpha} E-A\right) \neq 0$.

b) The SFOS system (11) is said to be impulse free if (11) is regular and $\operatorname{deg}\left(\operatorname{det}\left(s^{\alpha} E-A\right)\right)=\operatorname{rank} E$.

Lemma 2. The triplet $(E, A, \alpha)$ is called regular if and only if $\operatorname{det}\left(s^{\alpha} E-A\right) \neq 0$ for some $s \in \mathbb{C},[33-35]$.

Also, if triplet $(E, A, \alpha)$ is regular, we call SFOS system (11) regular, and consequently SFOS system is solvable.

Here, $t$ is the time in the operationinterval $J=\left[t_{0}, t_{0}+T\right]$, $J \subset R$, as well as $A, B$ and $\mathrm{C}$ are matrices with appropriate dimensions. It is assumed that $\operatorname{det} E=0$ as well as SFOS system is regular. Throughout this paper, let $C\left(\left[-\tau_{M}, 0\right], R^{n}\right)$ be the space of all continuous functions mapping the interval $\left[-\tau_{M}, 0\right]$ into $R^{n}$, where the consistent initial function $\psi_{x}(.) \in C\left(\left[-\tau_{M}, 0\right], R^{n}\right)$. Consider the following initial value problem (IVP) for fractional order nonsingular time delay system:

$$
\begin{gathered}
D^{\alpha} \boldsymbol{x}(t)=A_{0} x(t)+A_{1} x\left(t-\tau_{M}\right)+B u(t), \quad 0<\alpha<1 \\
x(t)=\psi_{x}(t), \quad-\tau_{M} \leq t \leq 0 .
\end{gathered}
$$

It is well known that the initial value problem (IVP) (11) is equivalent to the following Volterra integral equation with memory

$$
x(t)=\psi_{x}\left(t_{0}\right)+\frac{1}{\Gamma(\alpha)} \int_{t_{0}}^{t}(t-s)^{\alpha-1}\left(\begin{array}{l}
A_{0} x(s) \\
+A_{1} x\left(s-\tau_{M}\right) \\
+B u(s)
\end{array}\right) d s
$$

and its solutions are continuous [53]. As discussed in paper [33], applying the method of steps, we obtain the following Lemma 2 which generalizes well-known results of integerorder singular systems without delay[13] to fractional-order singular delay differential systems [54].

To obtain our main result, the following useful lemma is first listed.

Lemma 3. (see [52]) Assume that $(E, A)$ is regular and 
$\psi_{x}(t) \in C\left(\left[-\tau_{M}, 0\right], R^{n}\right)$ is the consistent initial function, then system (11) has a unique solution on $[0,+\infty]$.

The following assumptions on the system (11), (12) are imposed.

A1. The desired trajectories $y_{d}(t), x_{d}(t)$ are continuously differentiable on $[0, T]$.

A2. The desired output trajectory $y_{d}(t)$ is reachable, that is there exists a control input $u_{d}(t)$ such that

$$
\begin{aligned}
& E D^{\alpha} \boldsymbol{x}_{d}(t)=A_{0} x_{d}(t)+A_{1} x_{d}(t-\tau)+B u_{d}(t), \\
& 0<\alpha<1
\end{aligned}
$$

$$
y_{d}(t)=C x_{d}(t)
$$

A3. The system (7) is causal, and when $t<0$, is assumed $\psi_{i}(t)=\psi_{d}(t) \quad \forall t \in\left[-\tau_{M}, 0\right] \quad$ where $\quad x_{i}(t)=\psi_{i}(t)$ $\forall t \in\left[-\tau_{M}, 0\right]$ is the initial function of system (11) at $i-t h$ iteration, as well as $x_{i}(0)=x_{d}(0), i=0,1,2, \ldots$, holds for all iterations

A4. SFOS system is controllable and observable.

\section{Convergence analysis of $P D^{\alpha}$ type iterative learning control}

In this section, the convergence of ILC scheme given in the previous section is investigated. In order to track the desired output trajectory $y_{d}(t)$, and due to the complicity of the system (11), we take into account the $P D^{\alpha}$-type ILC algorithm to derive the control input sequences $u_{i}(t)$ such that the system output $y_{i}(t)$ tracks the desired output trajectory $y_{d}(t)$ as accurately as possible when $i$ goes to infinity for all $t \in[0, T]$.

Here, the following fractional order $P D^{\alpha}$ learning algorithm is considered which comprises control law a closedloop $P D^{\alpha}$ law. In that way, closed-loop fractional order $P D^{\alpha}$ learning algorithm takes the form of

$$
u_{i+1}(t)=u_{i}(t)+\Gamma \cdot e_{i+1}(t)+\Pi \cdot{ }_{0} D_{t}^{\alpha} e_{i+1}(t),
$$

where $\Gamma, \Pi$ are gain matrices of appropriate dimensions, $u(t)$ the value of the function at time. The expression $e_{i}(t)=y_{d}(t)-y_{i}(t)$ denotes the tracking error of the fractional order singular system at $i-t h$ iteration.

First of all, let us consider the updating law (19) and system (11), (12). A sufficient condition for convergence of a proposed feedback ILC is given by Theorem 1 and proved as follows.

Theorem 1: Consider the fractional order linear singular time-delay system governed by (11), (12) to which an closedloop $P D^{\alpha}$-type ILC algorithm (19) is applied, and assume that assumptions (A1)-(A4) are satisfied. If matrix $\Pi$, exist provided that

$$
\|[I-\Pi C \bar{B}]\| \leq \rho<1,
$$

where is $\bar{B}=(E+B \Pi C)^{-1}$ and matrix $\Pi$ is such that so $(E+B \Pi C)$ is invertible, then, when $i \rightarrow \infty$ the bounds of the tracking errors $\quad\left\|x_{d}(t)-x_{i}(t)\right\|, \quad\left\|y_{d}(t)-y_{i}(t)\right\|$ $\left\|y_{d}(t)-y_{i}(t)\right\|$, converge asymptotically to zero.

Proof. Let

$$
\begin{aligned}
& \delta h_{i}=h_{d}(t)-h_{i}(t), \quad h=x, x_{d}, u, u_{d}, f \\
& D^{\alpha} \delta h_{i}(t)=\delta h_{i}^{(\alpha)}=h_{d}^{(\alpha)}(t)-h_{i}^{(\alpha)}(t)
\end{aligned}
$$

It follows from (18) and (21) one observes that tracking error is:

$$
e_{i}^{(\alpha)}(t)=\frac{d^{(\alpha)}}{d t^{(\alpha)}}\left(y_{d}(t)-y_{i}(t)\right)=C \delta x_{i}^{(\alpha)}(t) .
$$

From (19), (22) we obtain:

$$
\delta u_{i+1}=\delta u_{i}-\Gamma C \delta x_{i+1}-\Pi C \delta x_{i+1}^{(\alpha)},
$$

Consequently, we obtain from $(7,18)$ :

$$
\begin{aligned}
E \delta x_{i+1}^{(\alpha)}(t) & =A_{0} \delta x_{i+1}(t)+ \\
& +A_{1} \delta x_{i+1}\left(t-\tau_{M}\right)+B \delta u_{i+1}(t)
\end{aligned}
$$

Substituting (23) into (24) we have

$$
\begin{aligned}
(E+B \Pi C) \delta x_{i+1}^{(\alpha)}(t) & =\left(A_{0}-B \Gamma C\right) \delta x_{i+1}(t)+ \\
& +A_{1} \delta x_{i+1}\left(t-\tau_{M}\right)+B \delta u_{i}(t)
\end{aligned}
$$

Using suitable gain matrix $\Pi$, as well as taking into account previously introduced assumptions, one can determine matrix $(E+B \Pi C)$ as invertible. Multiplying on the left side expression $(25)$ by $(E+B \Pi C)^{-1}$ it is not difficult to get

$$
\delta x_{i+1}^{(\alpha)}=\bar{A}_{0} \delta x_{i+1}(t)+\bar{A}_{1} \delta x_{i+1}\left(t-\tau_{M}\right)+\bar{B} \delta u_{i}(t)
$$

where are

$$
\begin{aligned}
& \bar{A}_{0}=(E+B \Pi C)^{-1}\left(A_{0}-B \Gamma C\right) \\
& \bar{B}=(E+B \Pi C)^{-1} B \\
& \bar{A}_{1}=(E+B \Pi C)^{-1} A_{1}
\end{aligned},
$$

By (21) via (26), we get (28)

$$
\begin{aligned}
\delta u_{i+1}(t) & =[I-\Pi C \bar{B}] \delta u_{i}(t)-\left[\Gamma C+\Pi C \bar{A}_{0}\right] \delta x_{i+1}(t) \\
& -\Pi C \bar{A}_{1} \delta x_{i+1}\left(t-\tau_{M}\right)
\end{aligned}
$$

Taking the standard norm, $\|()$.$\| of the above equation, and$ using the condition of Theorem 1, we find

$$
\begin{aligned}
& \left\|\delta u_{i+1}(t)\right\| \leq \rho\left\|\delta u_{i}(t)\right\|+\left\|\left[\Gamma C+\Pi C \bar{A}_{0}\right]\right\|\left\|\delta x_{i+1}(t)\right\|+ \\
& +\left\|\Pi C \bar{A}_{1}\right\|\left\|\delta x\left(t-\tau_{M}\right)\right\|= \\
& =\rho\left\|\delta u_{i}(t)\right\|+\beta_{0}\left\|\delta x_{i+1}(t)\right\|+\beta_{1}\left\|\delta x\left(t-\tau_{M}\right)\right\|
\end{aligned}
$$

where

$$
\beta_{0}=\left\|\left[\Gamma C+\Pi C \bar{A}_{0}\right]\right\|, \quad \beta_{1}=\left\|\Pi C \bar{A}_{1}\right\|
$$

Also, one can write the solutions of (24) in form of the equivalent Volterra integral equations and applying Lemma 2. and assumption $\mathrm{A} 3$, as:

$$
\delta x_{i+1}(t)=\frac{1}{\Gamma(\alpha)} \int_{0}^{t}(t-s)^{\alpha-1}\left(\begin{array}{l}
\bar{A}_{0} \delta x_{i+1}(s)+\bar{B} \delta u_{i}(s) \\
+\bar{A}_{1} \delta x_{i+1}\left(s-\tau_{M}\right)
\end{array}\right) d s
$$


Applying the norm $\|()$.$\| on the equation (31), we derive:$

$$
\begin{aligned}
& \left\|\delta x_{i+1}(t)\right\| \leq \frac{1}{\Gamma(\alpha)} \int_{0}^{t}\left|(t-s)^{\alpha-1}\right|\left\|\bar{A}_{0}\right\|\left\|\delta x_{i+1}(s)\right\| d s+ \\
& +\frac{1}{\Gamma(\alpha)} \int_{0}^{t}\left|(t-s)^{\alpha-1}\right|\left\|\overline{A_{1}}\right\|\left\|\delta x_{i}\left(s-\tau_{M}\right)\right\| d s+ \\
& +\frac{1}{\Gamma(\alpha)} \int_{0}^{t}\left|(t-s)^{\alpha-1}\right|\|\bar{B}\|\left\|\delta u_{i}(s)\right\| d s \\
& \leq \frac{a_{0}}{\Gamma(\alpha)} \int_{0}^{t}\left|(t-s)^{\alpha-1}\right|\left\|\delta x_{i+1}(s)\right\| d s+ \\
& +\frac{a_{1}}{\Gamma(\alpha)} \int_{0}^{t}\left|(t-s)^{\alpha-1}\right|\left\|\delta x_{i}\left(s-\tau_{M}\right)\right\| d s \\
& +\frac{b}{\Gamma(\alpha)} \int_{0}^{t}\left|(t-s)^{\alpha-1}\right|\left\|\delta u_{i}(s)\right\| d s+
\end{aligned}
$$

where $a_{0}=\|\bar{A}\|, \quad a_{1}=\left\|\bar{A}_{1}\right\|, \quad b=\|\bar{B}\|$. Moreover, taking $\lambda$ norm, we have

$$
\begin{gathered}
\left\|\delta x_{i+1}(t)\right\|_{\lambda} \leq \sup _{0 \leq t \leq T}\left\{\int_{0}^{t} e^{-\lambda t} \frac{|(t-s)|^{\alpha-1}}{\Gamma(\alpha)}\left[\begin{array}{l}
a_{0}\left\|\delta x_{i+1}(s)\right\|+ \\
a_{1}\left\|\delta x_{i+1}\left(s-\tau_{M}\right)\right\| \\
+b\left\|\delta u_{i}(s)\right\|
\end{array}\right] d s\right\} \\
\leq \sup _{0 \leq t \leq T} \int_{0}^{t} e^{-\lambda(t-s)} \frac{|(t-s)|^{\alpha-1}}{\Gamma(\alpha)} \sup _{0 \leq t \leq T} e^{-\lambda s}\left[\begin{array}{l}
a_{0}\left\|\delta x_{i+1}(s)\right\|+ \\
a_{1}\left\|\delta x_{i+1}\left(s-\tau_{M}\right)\right\| \\
+b\left\|\delta u_{i}(s)\right\|
\end{array}\right] d s
\end{gathered}
$$

or

$$
\begin{aligned}
\left\|\delta x_{i+1}(t)\right\|_{\lambda} \leq & \left(\begin{array}{l}
a_{0}\left\|\delta x_{i+1}(t)\right\|_{\lambda}+a_{1} e^{-\tau_{M}} \\
+b\left\|\delta u_{i}(t)\right\|_{\lambda}
\end{array}\right. \\
& \cdot \sup _{0 \leq t \leq T} \int_{0}^{t} e^{-\lambda(t-s)} d s \sup _{0 \leq t \leq T} \int_{0}^{t} \frac{|(t-s)|^{\alpha-1}}{\Gamma(\alpha)} d s .
\end{aligned}
$$

Furthermore, due to the fact $\left\|\delta x_{i+1}\left(t-\tau_{M}\right)\right\|_{\lambda} \leq\left\|\delta x_{i+1}(t)\right\| \lambda$, it holds that

$$
\begin{aligned}
\left\|\delta x_{i+1}(t)\right\|_{\lambda} \leq & \left(\begin{array}{l}
a_{0}\left\|\delta x_{i+1}(t)\right\|_{\lambda}+ \\
a_{1} e^{-\tau_{M}}\left\|\delta x_{i+1}(t)\right\|_{\lambda} \\
+b\left\|\delta u_{i}(t)\right\|_{\lambda}
\end{array}\right), \\
& \cdot \sup _{0 \leq t \leq T} \int_{0}^{t} e^{-\lambda(t-s)} d s \sup _{0 \leq t \leq T} \int_{0}^{t} \frac{|(t-s)|^{\alpha-1}}{\Gamma(\alpha)} d s .
\end{aligned}
$$

which implies that

$$
\begin{aligned}
& \left\|\delta x_{i+1}(t)\right\|_{\lambda} \leq\left(\left(a_{0}+a_{1} e^{-\tau_{M}}\right)\left\|\delta x_{i+1}(t)\right\|_{\lambda}+b\left\|\delta u_{i}(t)\right\|_{\lambda}\right) . \\
& T^{\alpha}\left(1-e^{-\lambda T}\right) /(\lambda \Gamma(\alpha+1)) .
\end{aligned}
$$

Introducing

$$
O\left(\lambda^{-1}\right)
$$

$O\left(\lambda^{-1}\right)=T^{\alpha}\left(1-e^{-\lambda T}\right) /(\lambda \Gamma(\alpha+1))$, which implies that (33) simplifies to

$$
\left\|\delta x_{i+1}(t)\right\|_{\lambda} \leq\left(\begin{array}{l}
\left(a_{0}+a_{1} e^{-\tau_{M}}\right)\left\|\delta x_{i+1}(t)\right\|_{\lambda} \\
+b\left\|\delta u_{i}(t)\right\|_{\lambda}
\end{array}\right) \cdot O\left(\lambda^{-1}\right)
$$

Consequently, it follows that

$$
\begin{gathered}
\left\|\delta x_{i+1}(t)\right\|_{\lambda} \leq \frac{b O\left(\lambda^{-1}\right)\left\|\delta u_{i}(t)\right\|_{\lambda}}{\left(1-\left(a_{0}+a_{1} e^{-\tau_{M}}\right) O\left(\lambda^{-1}\right)\right)} \leq \\
\leq O_{\gamma}\left(\lambda^{-1}\right)\left\|\delta u_{i}(t)\right\|_{\lambda}
\end{gathered}
$$

It then follows that there exists $\lambda$ large enough such that

$$
\lambda \Gamma(\alpha+1)-\left(a_{0}+a_{1} e^{-\tau_{M}}\right)\left(1-e^{-\lambda T}\right) T^{\alpha}>0
$$

Summarizing, we see that taking the $\lambda$ - norm again on the expression (29) leads to:

$$
\left\|\delta u_{i+1}(t)\right\|_{\lambda} \leq \rho\left\|\delta u_{i}(t)\right\|_{\lambda}+\left(\beta_{0}+\beta_{1} e^{-\tau_{M}}\right)\left\|\delta x_{i+1}(t)\right\|_{\lambda}
$$

Concerning equations (36) and (38) we have

$$
\begin{aligned}
\left\|\delta u_{i+1}\right\|_{\lambda} & \leq\left(\rho+\left(\beta_{0}+\beta_{1} e^{-\tau_{M}}\right) O_{\gamma}\left(\lambda^{-1}\right)\right)\left\|\delta u_{i}\right\|_{\lambda} \\
& =\rho^{\prime}\left\|\delta u_{i}\right\|_{\lambda}
\end{aligned}
$$

It then follows that there exists $\lambda$ large enough such that

$$
\rho^{\prime}=\left(\rho+\left(\beta_{0}+\beta_{1} e^{-\tau_{M}}\right) O_{\gamma}\left(\lambda^{-1}\right)\right)<1
$$

Therefore, according to Lemma1, [4] it can be concluded that:

$$
\lim _{i \rightarrow \infty}\left\|\delta u_{i}\right\|_{\lambda} \rightarrow 0
$$

Moreover, due to the uniqueness and existence theorem for fractional order singular system, $[32,33]$ one can conclude that

$$
\lim _{i \rightarrow \infty} x_{i}(t)=x_{d}(t), \lim _{i \rightarrow \infty} y_{i}(t)=y_{d}(t),
$$

This completes the proof.

Further, we consider the case of the fractional order $\alpha \in(0,1)$ uncertain singular system nonautonomous singular linear system which can be written as pseudo state space equation and output equation:

$$
\begin{aligned}
& E D^{\alpha} \boldsymbol{x}(t)=A_{0} x(t)+A_{!} x\left(t-\tau_{M}\right)+B u(t)+\eta(t), \\
& 0<\alpha<1 \\
& \boldsymbol{y}(t)=C \boldsymbol{x}(t),
\end{aligned}
$$

with associated consistent function of initial state (13). Function $\xi_{i}(t) \in R^{n}$ represents uncertainty of the system, and introduces next assumption:

A5. The uncertainty term $\xi_{i}(t) \in R^{n}$ is bounded as follows, $\forall t \in[0, T]$ and $\forall i \rightarrow\left\|\xi_{i}(t)\right\| \leq d_{\xi}$, where $d_{\xi}$ is positive constant.

Before giving the other main result, we give the following Lemma 4 [55]:

Lemma 4. Suppose a real positive series $\left\{a_{n}\right\}_{1}^{\infty}$ satisfies

$$
\begin{aligned}
& a_{n} \leq \rho_{1} a_{n-1}+\rho_{2} a_{n-2}+\ldots+\rho_{N} a_{n-N}+\varepsilon \\
& (n=N+1, N+2, \ldots,)
\end{aligned}
$$


where $\rho_{i} \geq 0(i=1,2, \ldots, N), \varepsilon>0$ and $\rho=\sum_{i=1}^{N} \rho_{i}<1$. Then the following holds:

$$
\lim _{n \rightarrow \infty} a_{n} \leq \varepsilon /(1-\rho)
$$

Theorem 2. For the fractional order singular system (45), (46) with the $P D^{\alpha}$ - type ILC scheme (19), and the assumptions A1-A5 where the convergence condition is given by (20), then when $i \rightarrow \infty$ the bounds of the tracking errors $\left\|x_{d}(t)-x_{i}(t)\right\|, \quad\left\|y_{d}(t)-y_{i}(t)\right\|, \quad\left\|u_{d}(t)-u_{i}(t)\right\|, \quad$ converge asymptotically to a residual ball centered at the origin.

Proof: The proof follows from the proof of Theorem 1.

Namely, from (45), (46) one can easily find that

$$
E \delta x_{i+1}^{(\alpha)}=A \delta x_{i+1}+B \delta u_{i+1}-\xi_{i+1}
$$

Multiplying on the left side expression (49) by $(E+B \Pi C)^{-1}$ we obtain (50) in the form

$$
\delta x_{i+1}^{(\alpha)}=\bar{A} \delta x_{i+1}+\bar{B} \delta u_{i}-G \xi_{i+1}
$$

where we adopted

$$
\begin{aligned}
& \bar{A}=(E+B \Pi C)^{-1}(A-B \Gamma C), \\
& \bar{B}=(E+B \Pi C)^{-1} B \Lambda, \\
& G=(E+B \Pi C)^{-1}
\end{aligned}
$$

By replacing (50) into (25), we obtain

$$
\delta u_{i+1}=[I-\Pi C \bar{B}] \delta u_{i}-[\Gamma C+\Pi C \bar{A}] \delta x_{i+1}+\Pi C G \xi_{i+1}
$$

Estimating the norms of (52) with $\|()$.$\| and using the$ condition of Theorem 2 one gets

$$
\begin{aligned}
& \left\|\delta u_{i+1}\right\| \leq \rho\left\|\delta u_{i}\right\|+\|[\Gamma C+\Pi C \bar{A}]\|\left\|\delta x_{i+1}\right\|+\|\Pi C G\|\left\|\xi_{i+1}\right\| \\
& =\rho\left\|\delta u_{i}\right\|+\beta_{0}\left\|\delta x_{i+1}\right\|+\gamma_{0}\left\|\xi_{i+1}\right\| \leq \\
& \leq \rho\left\|\delta u_{i}\right\|+\beta_{0}\left\|\delta x_{i+1}\right\|+\gamma_{0} d_{\xi}
\end{aligned}
$$

Also, one can write the solutions of (45) in the form of the equivalent Volterra integral equations using assumption A5, as:

$$
\delta x_{i+1}(t)=\frac{1}{\Gamma(\alpha)} \int_{0}^{t}(t-s)^{\alpha-1}\left(\begin{array}{l}
\bar{A} \delta x_{i+1}(s)+\bar{B} \delta u_{i}(s) \\
-G \xi_{i+1}(s)
\end{array}\right) d s
$$

In similar manner, applying the norm $\|()$.$\| on the equation$ (54), if there exists unique solution, [32,33] where are, $a=\|A\|, b=\|B\|, g=\|G\|$ and applying $\lambda$ norm, we have

$$
\left\|\delta x_{i+1}(t)\right\|_{\lambda} \leq \sup _{0 \leq t \leq 1 T} e^{-\lambda t}\left\{\begin{array}{l}
\frac{a}{\Gamma(\alpha)} \int_{0}^{t}\left|(t-s)^{\alpha-1}\right|\left\|\delta x_{i+1}(s)\right\| d s+ \\
+\frac{b}{\Gamma(\alpha)} \int_{0}^{t} \mid(t-s)^{\alpha-1}\left\|\delta u_{i}(s)\right\| d s+ \\
+\frac{g \cdot d_{\xi}}{\Gamma(\alpha)} \int_{0}^{t}\left|(t-s)^{\alpha-1}\right| d s
\end{array}\right\}
$$

$$
\begin{gathered}
\left\|\delta x_{i+1}(t)\right\|_{\lambda} \leq \sup _{0 \leq t \leq T}\left\{\int_{0}^{t} e^{-\lambda t} \frac{|(t-s)|^{\alpha-1}}{\Gamma(\alpha)}\left[\begin{array}{l}
a\left\|\delta x_{i+1}(s)\right\|+ \\
+b\left\|\delta u_{i}(s)\right\|
\end{array}\right] d s\right\}+ \\
+\sup _{0 \leq t \leq T} e^{-\lambda t}\left\{\int_{0}^{t} \frac{\left.(t-s)\right|^{\alpha-1}}{\Gamma(\alpha)}\left[g \cdot d_{\xi}\right] d s\right\} \\
\left\|\delta x_{i+1}(t)\right\|_{\lambda} \leq \\
\leq \sup _{0 \leq t \leq T} \int_{0}^{t} e^{-\lambda(t-s)} \frac{\left.(t-s)\right|^{\alpha-1}}{\Gamma(\alpha)} \sup _{0 \leq t \leq T} e^{-\lambda s}\left[\begin{array}{l}
a\left\|\delta x_{i+1}(s)\right\| \\
+b\left\|\delta u_{i}(s)\right\|
\end{array}\right] d s+ \\
+g \cdot d_{\xi} \sup _{0 \leq t \leq T} e^{-\lambda t}\left\{\int_{0}^{t} \frac{\left.(t-s)\right|^{\alpha-1}}{\Gamma(\alpha)} d s\right\}
\end{gathered}
$$

or,

$$
\begin{aligned}
& \left\|\delta x_{i+1}(t)\right\|_{\lambda} \leq\left(a\left\|\delta x_{i+1}(t)\right\|_{\lambda}+b\left\|\delta u_{i}(t)\right\|_{\lambda}\right) . \\
& \frac{\left(1-e^{-\lambda T}\right)}{\lambda} \frac{T^{\alpha}}{\Gamma(\alpha+1)}+\left[g \cdot d_{\xi}\right] \frac{e^{-\lambda t^{*}}\left(t^{*}\right)^{\alpha}}{\Gamma(\alpha+1)}, \\
& t^{*} \in[0, T]
\end{aligned}
$$

Defining respectively $O\left(\lambda^{-1}\right)$ and $O^{*}\left(\lambda^{-1}\right)$ as

$$
\begin{aligned}
& O\left(\lambda^{-1}\right)=\frac{\left(1-e^{-\lambda T}\right)}{\lambda} \frac{T^{\alpha}}{\Gamma(\alpha+1)}, \\
& O^{*}\left(\lambda^{-1}\right)=e^{-\lambda t^{*}} \frac{\left(t^{*}\right)^{\alpha}}{\Gamma(\alpha+1)}, t^{*} \in[0, T]
\end{aligned}
$$

where (56) simplifies to

$$
\begin{aligned}
& \left\|\delta x_{i+1}(t)\right\|_{\lambda} \leq\left(a\left\|\delta x_{i+1}(t)\right\|_{\lambda}+b\left\|\delta u_{i}(t)\right\|_{\lambda}\right) \cdot O\left(\lambda^{-1}\right) \\
& +\left[g \cdot d_{\xi}\right] O^{*}\left(\lambda^{-1}\right),
\end{aligned}
$$

then we can get

$$
\begin{aligned}
& \left\|\delta x_{i+1}(t)\right\|_{\lambda} \leq \frac{b}{1-a O\left(\lambda^{-1}\right)}\left\|\delta u_{i}(t)\right\|_{\lambda} \cdot O\left(\lambda^{-1}\right)+ \\
& \frac{\left[g \cdot d_{\xi}\right] O^{*}\left(\lambda^{-1}\right)}{1-a O\left(\lambda^{-1}\right)} \leq O_{b}\left(\lambda^{-1}\right)\left\|\delta u_{i}(t)\right\|_{\lambda}+\left[g \cdot d_{\xi}\right] O^{*}\left(\lambda^{-1}\right),
\end{aligned}
$$

Then, if a sufficiently large $\lambda$ is used, one can obtain that:

$$
\lambda \Gamma(\alpha+1)-a\left(1-e^{-\lambda T}\right) T^{\alpha}>0 .
$$

Taking the $\lambda$-norm of the above, equation (53) leads to:

$$
\left\|\delta u_{i+1}\right\|_{\lambda} \leq \rho\left\|\delta u_{i}\right\|_{\lambda}+\beta_{0}\left\|\delta x_{i+1}\right\|_{\lambda}+\delta
$$

Finally, taking into account (59) we have

$$
\begin{aligned}
\left\|\delta u_{i+1}\right\|_{\lambda} & \leq\left(\rho+\beta_{0} O_{b}\right)\left(\lambda^{-1}\right)\left\|\delta u_{i}\right\|_{\lambda}+ \\
& +\beta_{0}\left[g \cdot d_{\xi}\right] O^{*}\left(\lambda^{-1}\right)+\delta \\
\leq & \bar{\rho}\left\|\delta u_{i}\right\|_{\lambda}+\bar{\varepsilon}
\end{aligned}
$$

So that, there exists a sufficient large $\lambda$ satisfying

$$
\rho^{\prime}=\left(\rho+\beta_{0} O_{y}\left(\lambda^{-1}\right)\right)<1
$$

Therefore, taking into account Lemmas 4,1 [54], it yields:

$$
\lim _{i \rightarrow \infty}\left\|\delta u_{i}\right\|_{\lambda} \leq \frac{1}{1-\rho^{\prime}} \varepsilon,
$$

This completes the proof of Theorem 2. 
Remark 1. In the case of no uncertainty, i.e., $\xi_{i}(t) \in R^{n}$ one can obtain that when $i \rightarrow \infty$ bounds of the tracking errors $\left\|x_{d}(t)-x_{i}(t)\right\|,\left\|y_{d}(t)-y_{i}(t)\right\|$, and $\left\|u_{d}(t)-u_{i}(t)\right\|$ converge asymptotically to zero, as stated in Theorem 1, (i.e., $\left.\xi_{i}(t)=0\right)$.

\section{Simulation results}

In this section, we provide an example to illustrate the applicability of the proposed method. Consider the following fractional order linear singular time delay system in state space form described by

$$
\begin{gathered}
{\left[\begin{array}{ll}
1 & 0 \\
0 & 0
\end{array}\right]\left[\begin{array}{l}
D^{0.5} x_{1}(t) \\
D^{0.5} x_{2}(t)
\end{array}\right]=\left[\begin{array}{cc}
1 & 2 \\
1 & -1
\end{array}\right]\left[\begin{array}{l}
x_{1}(t) \\
x_{2}(t)
\end{array}\right]+} \\
{\left[\begin{array}{ll}
1 & 0 \\
0 & 1
\end{array}\right]\left[\begin{array}{l}
x_{1}\left(t-\tau_{M}\right) \\
x_{2}\left(t-\tau_{M}\right)
\end{array}\right]+\left[\begin{array}{ll}
1 & 0 \\
0 & 1
\end{array}\right]\left[\begin{array}{l}
u_{1}(t) \\
u_{2}(t)
\end{array}\right]} \\
{\left[\begin{array}{l}
y_{1}(t) \\
y_{2}(t)
\end{array}\right]=\left[\begin{array}{ll}
1 & 0 \\
0 & 1
\end{array}\right]\left[\begin{array}{l}
x_{1}(t) \\
x_{2}(t)
\end{array}\right]}
\end{gathered}
$$

where $t \in[0,1], \alpha=0.5, \tau_{M}=0.1$ and

$$
\psi_{d 1}(t)=\psi_{d 2}(t)=-0.1 t,-0.1 \leq t \leq 0 .
$$

The desired trajectories are given by

$$
\begin{gathered}
y_{d 1}(t)=1.5 t \cdot(1-t), y_{d 2}(t)=0.5 t^{2}, \\
y_{d 1,2}(0)=y_{i 1,2}(0)=0
\end{gathered}
$$

The gain matrices are

$$
\Pi=\left[\begin{array}{cc}
0.9 & 0.3 \\
0 & 0.9
\end{array}\right], \quad \Gamma=\left[\begin{array}{cc}
0.7 & 0.2 \\
0 & 0.7
\end{array}\right]
$$

It is easy to show that the pair (E, A) is regularand $\|[I-\Pi C \bar{B}]\|=0.7<1$. Simulation results in Figures $1-4$ show the effectiveness of the developed ILC control scheme for the system $(45,46)$. It can be seen that the system output $y(t)$ is capable of approaching the desired trajectory accurately within few iterations. Also, it can be seen (see Figures 1 and 2) that the proposed requirement for the tracking performance is achieved at the seventh iteration. The ILC rule (19) is used, (Figures 3 and 4) show the tracking performance of the ILC system outputs on the interval $t \in[0,1]$.

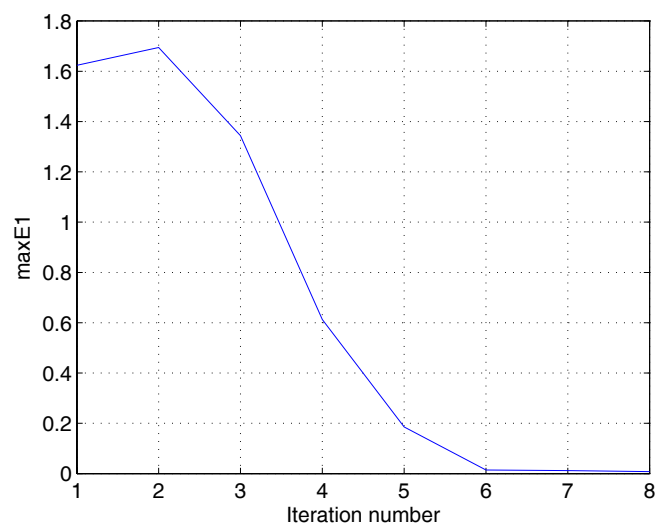

Figure 1. The sup-norm of tracking error $e_{1}(t)$ in each iteration

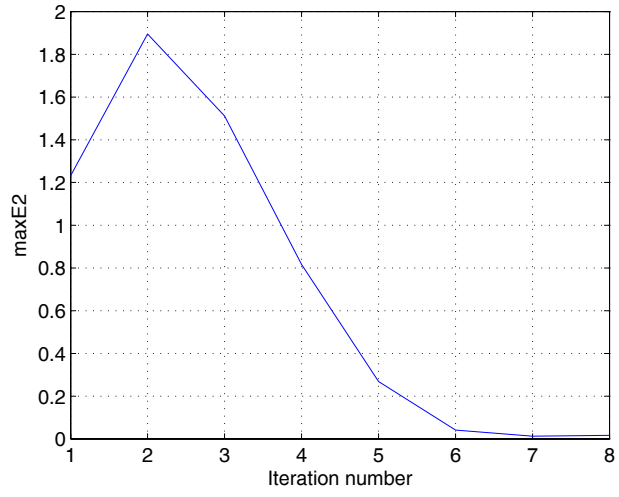

Figure 2. The sup-norm of tracking error $e_{2}(t)$ in each iteration

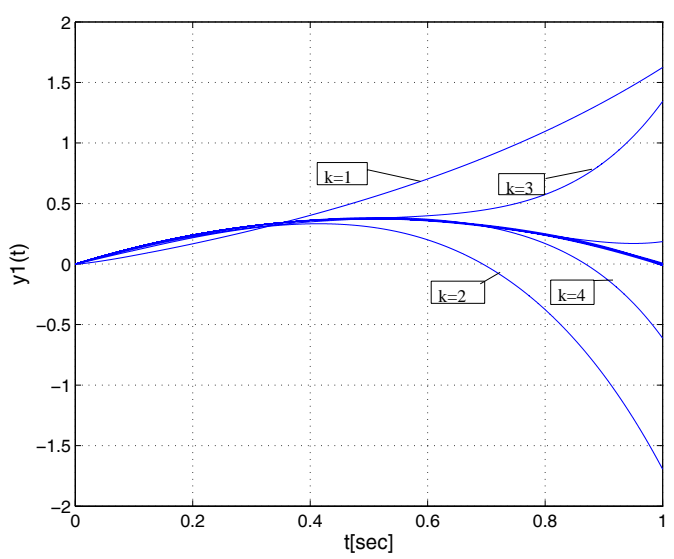

Figure 3. The tracking performance of the system output $y_{1}(t)$ : solid line, $y_{d 1}(t)$ : bold line $), \mathrm{k}$-number of iteration

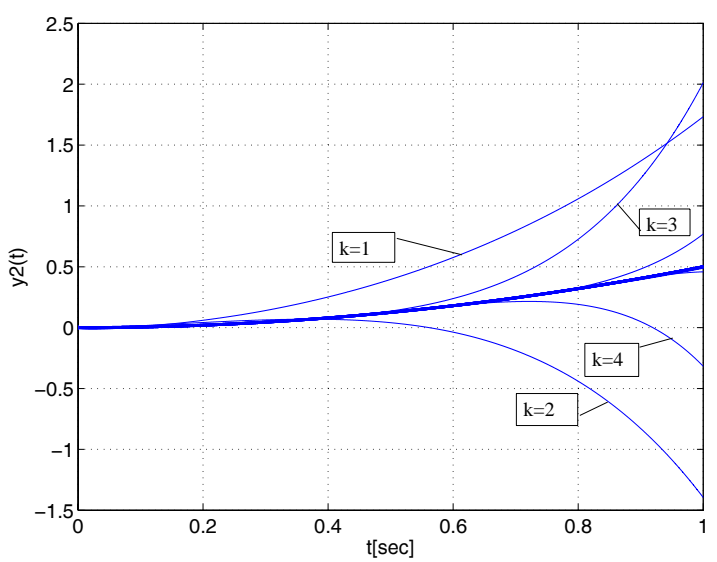

Figure 4. The tracking performance of the system output $y_{2}(t)$ : solid line, $y_{d 2}(t):$ bold line)

\section{Conclusions}

In this contribution, $P D^{\alpha}$ type of iterative learning feedback control for given class of fractional order linear singular time-delay system is investigated. The sufficient conditions for the convergence in time domain of a proposed ILC were given by the corresponding theorem and proved. Also, for the first time, we proposed a robust $P D^{\alpha}$ type of iterative learning feedback control for given class of uncertain, fractional order, singular systems which guaranteed the convergence conditions in presence of bounded uncertainty of the system. 
Finally, the theoretical results have been verified through numerical simulations which demonstrate the effectiveness of the proposed robust $P D^{\alpha}$ ILC scheme for a class of fractional order linear singular time-delay system.

\section{Acknowledgement}

This work is supported by the Ministry of Education, Science and Technological Development of the Republic of Serbia through projects TR 35006, III 41006 (M.L) and TR 33047 (P.M)

\section{Literature}

[1] BIEN,Z., XU,J.: Iterative Learning Control: Analysis, Design, Integration and Applications, Kluwer Academic Publishers, 1989.

[2] MOORE,K.L., DAHLEH,M., BHATTACHARYYA,S.P.: Iterative learning control: A survey and new results, Journal of Field Robotics, 1992, 9(5), pp.563-594.

[3] MOORE,K.L.: Iterative learning control for deterministic systems, Advances in Industrial Control, Springer-Verlag, London, UK, 1993.

[4] AHN,H.S., MOORE,K., CHEN,Y.: Iterative learning control robustness and monotonic convergence for interval systems, SpringerVerlag London Limited, London, UK, 2007.

[5] UCHIYAMA,M.: Formulation of high-speed motion pattern of a mechanical arm by trial (in Japanese), Trans. SICE (Soc. Instrum. Control Eng.), 1978, 14, pp.706-712.

[6] ARIMOTO S., KAWAMURA S., MIYAZAKI F.: Bettering operation of robots by learning, J. Rob. Syst., 1984, 2(1), pp.123-140.

[7] PARK,K.H., BIEN,Z.: Intervalized iterative learning control for monotonic convergence in the sense of sup-norm, Int. J. Control, 2005, Vol.78, No.15, pp.1218-1227.

[8] MADADY,A.: PID type iterative learning control with optimal gains, Int. J. Control Autom. Syst., 2008, Vol.6, No.2, pp.194-203.

[9] BRISTOW,D.A., THARAYIL,M., ALLEYNE,A.G.: A survey of iterative learning control, IEEE Control Syst. Mag., 2006, Vol.26, No.3, pp. 96-114.

[10] BIEN,Z., XU,J.X.: Iterative Learning Control: Analysis, Design, Integration and Applications, Boston: Kluwer Academic Publishers, 1998.

[11] XU,J.X., TAN,Y.: Linear and Nonlinear Iterative Learning Control. Lecture Notes in Control and Information Sciences, New York: Springer, 2003.

[12] ZHANG,B., TANG,G., ZHENG,S.: PD-type iterative learning control for nonlinear time delay system with external disturbance, Journal of Systems Engineering and Electronics, September 2006, Vol.17, No.3, pp. 600-605.

[13] DAI,L.: Singular Control Systems, Springer-Verlag New York, Inc., 1989

[14] CAMPBELL,S.L.V.: Singular systems of differential equations II, Pitman Publishing (UK), 1982.

[15] WANG,Y., ZOU,Y., LIU,Y., SHI,X., ZUO,Z.: Average dwell time approach to finite-time stabilization of switched singular linear systems, J. Franklin Inst., 2015, 352 (7), pp.2920-2933.

[16] MÜLLER,P.C.: Stability of Linear Mechanical Systems with Holonomic Constraints, Appl. Mech. Rev., 1993, 46(11), pp.160-164.

[17] ROSENBROCK,H.H.: Structural properties of linear dynamical systems, Int. J. Control, 1974, 20(2), pp.191-202.

[18] BUZUROVIC,I.: Dynamic model of medical robot represented as descriptor system, International journal of information and systems sciences, 2007, 2(2), pp.316-333.

[19] KOSMATOPOUlOS,E.N., CHRISTODOUlOU,M.A.: Stability analysis of differential-algebraic neural networks, In Proceeding 12th World Conference of IFAC. Sydney, AUSTRALIA, 1992, 6(4), pp.1-5.

[20] PIAO, FX, ZHANG, QL: Iterative learning control for linear singular systems. Control Decis., 2007, 22(3), pp.349-351.

[21] TIAN,S.P., ZHOU,X.J.: State tracking algorithm for a class of singular ILC systems. J. Syst. Sci. Math. Sci., 2012, 32(6), pp. 731738.

[22] TIAN,S., Q., LIU,X., DAI,J., ZHANG,B.: A PD-type iterative learning control algorithm for singular discrete systems, Adv. Differ. Equ., 2016, (1), p.321.
[23] MILLER,K.S., ROSS,B.: An Introduction to the Fractional Calculus and Differential Equations. Wiley, New York, USA, 1993.

[24] PODLUBNY,I.: Fractional Differential Equations. Academic Press, San Diego, 1999.

[25] KILBAS,A.A., SRIVASTAVA,H.M., TRUJILLO,J.J.: Theory and Applications of Fractional Differential Equations. North-Holland Mathematics Studies, Elsevier, Amsterdam, NEDERLAND, 2006, Vol.204.

[26] LAKSHMIKANTHAM,V., LEELA,S., VASUNDHARA,D.J,: Theory of Fractional Dynamic Systems. Cambridge Academic Publishers, Cambridge, 2009.

[27] DIETHELM,K.: The Analysis of Fractional Differential Equations. Springer, Berlin, 2010.

[28] MONJE,C.A., CHEN,Y.Q., VINAGRE,B.M., XUE,D.Y., FELIU,B.V.: Fractional-order Systems and Controls :Fundamentals and Applications, London:Springer-Verlag, 2010.

[29] SKRUCH P., MITKOWSKI,W.: Fractional-Order Models of the Ultracapacitors, In Mitkowski W, Kacprzyk J and Baranowsk J (eds) Advances in the Theory and Applications of Non-integer Order Systems Springer, SWITZERLAND, 2013, pp.281-294.

[30] KACZOREK,T.: Singular fractional continuous-time and discrete-time linear systems, Acta mechanica et automatica, 2013, (7)1, pp.26-33

[31] ASHAYERI,L., SHAFIEE,M., MENHAJ,M.B.: Optimal control of fractional-order singular system via Block pulse functions, 20th Iranian Conference on Electrical Engineering, (ICEE2012), 15-17 May 2012, Tehran, IRAN, 2012, pp. 994-999.

[32] YU,Y., JIAO,Z., SUN,C.Y.: Sufficient and necessary condition of admissibility for fractional-order singular system, Acta Automatica Sinica, 2013, Vol.39, No.12, pp. 2160-2164.

[33] ZHANG,Z., WEI,J.: Some results of the degenerate fractional differential system with delay, Computers and Mathematics with Applications, 2011, 62 , pp.1284-1291.

[34] ZHANG,H., WU,D., CAO,J., ZHANG,H.: Stability Analysis for Fractional-Order Linear Singular Delay Differential Systems, Discrete Dynamics in Nature and Society, Vol.2014, Art.ID 850279, http://b dx.doi.org/10.1155/2014/850279, 2014.

[35] ZHANG,H., CAO,J., JIANG,W.: Reachability and Controllability of Fractional Singular Dynamical Systems with Control Delay, Journal of Applied Mathematics, Vol.2013, Article ID 567089, 10 pages http://dx.doi.org/10.1155/2013/567089, 2013.

[36] PRELI,C.Y.Q., MOORE,K.L.: On $D^{\alpha}$ type iterative learning control, In Proc. 40th IEEE Conference on Decision and Control, 2001, Orlando, FL USA, pp.4451-4456.

[37] LAZAREVIĆ,M.P.: $P D^{\alpha}$-type iterative learning control for fractional LTI system, 16th Int. Cong. CHISA 2004, G2.9, Praha, CZECH REPUBLIC, 22-26 August 2004.

[38] LAZAREVIĆ,M.: Iterative Learning Feedback Control for Nonlinear Fractional Order System-PDalpha Type, In: Proceedings of the 4th IFAC Workshop Fractional Differentiation and its Applications, FDA2010. Badajoz, SPAIN, 18-20 October 2010, Ar.FDA-148.

[39] LI,Y., CHEN,Y.Q., AHN,H.S.: Fractional-order iterative learning control for fractional-order linear systems, Asian J. Control, 2011, Vol.13, No.1, pp.54-63.

[40] LI,Y., CHEN,Y.Q., AHN,H.S.: On the PD $\alpha$-type iterative learning control for the fractional-order nonlinear systems, Proceedings of the American Control Conference, San Francisco, USA, 2011, pp. 43204325.

[41] LAN,Y.H.: Iterative learning control with initial state learning for fractional order nonlinear systems, Comput. Math. Appl., 2012, Vol.64, No.10, pp.3210-3216.

[42] LAN,Y.H., ZHOU,Y.: High-order D $\alpha$-type iterative learning control for fractional-order nonlinear time-delay systems, J. Optim. Theory Appl., 2013, Vol.156, No.1, pp.153-166.

[43] LAZAREVIĆ,M., MANDIĆ,P.: Feedback-feedforward iterative learning control for fractional-order uncertain time delay system-PD alpha type, ICFDA'14 Catania, ITALIA, 23-25 June 2014, IE86.

[44] LAZAREVIĆ,P.M.: Iterative Learning Control of Integer and Noninteger Order: an Overview, Scientific Technical Review, ISSN 1820-0206, 2014, Vol.64, No.1, pp.35-47.

[45] LAZAREVIĆ,P.M.: Some New Results on Iterative Learning Control of Noninteger Order, Scientific Technical Review, ISSN 1820-0206, 2014, Vol.64, No.2, pp.31-39.

[46] YAN,L., WEI,J.: Fractional order nonlinear systemswith delay in iterative learning control, Appl. Math.Comput., 2015, Vol.257, pp. 546-552. 
[47] LIU,S., WANG,J.R.: Fractional order iterative learning control with randomly varying trial lengths, J. Frankl. Inst., January 2017, Vol.354, No.2, pp.967-992.

[48] LAZAREVIĆ,P.M., TZEKIS,P.: Iterative learning feeback control for singular fractional order system-PDa type, IcETRAN 2014, Vrnjačka Banja, SERBIA, 2-5 June 2014, ISBN 978-86-80509-70-9, pp. AUI2.3,1-6.

[49] LAZAREVIĆ,M., TZEKIS,P.: Robust second-order PD type iterative learning control for a class of uncertain fractional-order singular systems, Journal of Vibration and Control, 2016, Vol. 22(8), pp. 2004 2018.

[50] LAZAREVIĆ,M., ĐUROVIĆ,N., CVETKOVIĆ,B., MANDIĆ,P., BUČANOVIĆ,LJ.: Fractional-order Iterative Learning Control for Singular Fractional order System: $(P)-P D \alpha$ Type, Scientific Technical Review, ISSN 1820-0206, 2016, Vol.66, No.3, pp.40-49.

[51] CVETKOVIĆ,B., LAZAREVIĆ,M., DJUROVIĆ,N., MANDIĆ,P.: Open-closed loop fractional-order iterative learning control for singular fractional-order system, International Conference on Fractional Differentiation and its Application, ICFDA2016, 18-20 July 2016, Novi Sad, SERBIA, 2016, pp.404-414.
[52] LAZAREVIĆ,M., ĐUROVIĆ, N., CVETKOVIĆ,B., MANDIĆ,P., CAJIĆ,M.: Pdalpha Type Iterative Learning Control for Fractionalorder Singular Time-delay System, 29th Chinese Control And Decision Conference (CCDC), 28-30 May 2017, Chongqing, CHINA, ISBN: 978-1-5090-4656-0,2017, pp.1905-1910.

[53] LAKSHMIKANTHAM,V.: Theory of fractional functional differential equations, Nonlinear Analysis: TMA, 2008, Vol.69, No.10, pp. 33373343.

[54] ZHANG,X.: Some results of linear fractional order time-delay system, Applied Mathematics and Computation, 2008, Vol.197, No.1, pp. 407411.

[55] CHEN,Y, GONG,Z, WEN,C.: Analysis of a high-order iterative learning control algorithm for uncertain nonlinear systems with state delays, Automatica, 1998, 34(3): pp.345-353.

\title{
Iterativno upravljanje učenjem u zatvorenoj petlji necelog reda za singularni sistem sa kašnjenjem necelog reda: $P D^{\alpha}$ tip
}

\author{
U ovom radu razmatrano je iterativno upravljanje učenjem u zatvorenoj petlji (ILC) - $P D^{\alpha}$ tip linearnim singularnim \\ sistemom sa kašnjenjem necelog reda. Dati su dovoljni uslovi za konvergenciju u vremenskom domenu predloženog PD-alfa \\ tipa ILC za datu klasu linearnog singularnog sistema sa kašnjenjem necelog reda zajedno sa odgovarajućom teoremom i \\ dokazom. Takođe, po prvi put je u ovom radu predloženi tip $P D^{\alpha}$ ILC primenjen za datu klasu linearnih singularnih sistema \\ sa kašnjenjem necelog reda sa neizvesnošću. Konačno, valjanost predloženog ILC algoritma upravljanja za razmatranu klasu \\ singularnih sistema je potvrđena sa adekvatnom numeričkom simulacijom. \\ Ključne reči: singularni sistem, linearni sistem, sistem sa kašnjenjem, robotizovani sistem, zatvorena petlja, konvergencija, \\ algoritam upravljanja, iterativno upravljanje.

\section{Итеративное управление обучением в замкнутом цикле не целого порядка для особой сингулярной системы с незапланированной задержкой: типа $P D^{\alpha}$}

\begin{abstract}
В этой статье рассматривается итеративное управление замкнутым циклом обучения (ILC) - $P D^{\alpha}$ тип линейной сингулярной системы с запаздыванием не целого порядка. Имеются достаточные условия сходимости во временной области предложенного ILC типа PD-alpha для данного класса линейной сингулярной системы с незапланированным запаздыванием вместе с соответствующей теоремой и доказательством. Кроме того, впервые в данной работе предложенный $P D^{\alpha}$ ILC типа применяется к данному классу линейных сингулярных систем с запаздыванием не целого порядка с неопределённостью. Наконец, правильность предложенного алгоритма управления ILC для рассматриваемого класса сингулярных систем была подтверждена адекватным численным моделированием.
\end{abstract}

Ключевые слова: сингулярная система, линейная система, система задержки, роботизированная система, замкнутый контур, сходимость, алгоритм управления, итеративное управление.

\section{Contrôle itératif de l'étude dans la boucle fermée de l'ordre fractionnel pour le système singulier à retard: type $P D$ alpha}

\footnotetext{
Dans ce papier on considère le contrôle itératif par l'étude dans la boucle fermée (ILC) du type PD alpha du système singulier linéaire à retard de l'ordre fractionnel. On a donné les conditions suffisantes pour la convergence dans le domaine temporel du type PD alpha ILC pour la classe donnée du système singulier linéaire à retard de l'ordre fractionnel avec le théorème correspondant ainsi que sa preuve. Pour la première fois dans ce travail le type proposé PD alpha ILC a été appliqué pour la classe donnée des systèmes linéaires singuliers à retard de l'ordre fractionnel avec incertitude. Finalement la validité de l'algorithme ILC proposé du contrôle pour la classe considérée des systèmes singuliers a été confirmée par la simulation numérique correspondante.
}

Mots clés: système singulier, système linéaire, système à retard, système robotisé, boucle fermée, convergence, algorithme de contrôle, itérativement. 